\title{
Assessment of Copper, Ceruloplasmin, Total Proteins and Albumin in Gestational Hypertension
}

\author{
${ }^{1}$ V. Durga Prasad, ${ }^{2}$ Shabana Shireen , ${ }^{3}$ G. V. Ramana , ${ }^{4}$ T. Shalini Gupta \\ ${ }^{I}$ Assistant Professor, Biochemistry Department, Konaseema Institute of Medical Sciences and Research \\ Foundation, Amalapuram, Andhra Pradesh \\ ${ }^{2}$ Professor, Biochemistry Department, Dr. PSIMS \& RF, Chinna Avutpalli, Vijayawada, Andhra Pradesh \\ ${ }^{3}$ Professor, Biochemistry Department, Dr. PSIMS \&RF, Chinna Avutpalli, Vijayawada, Andhra Pradesh \\ ${ }^{4}$ Assistant Professor, Department of Obst. \& Gynaec, Vijayawada, Andhra Pradesh
}

\begin{abstract}
:
Background: Gestational hypertension is defined as hypertension arising after mid-pregnancy and is distinguished from preeclampsia by the absence of proteinuria. Some of the women with gestational hypertension progress to preeclampsia. Preeclampsia is associated with increased oxidative stress which is known to be one of the main pathological mechanisms responsible for the mortality and morbidity associated with the condition. Proteinuria though not essential for the diagnosis of preeclampsia, is the common clinical and diagnostic feature of the disorder in women with hypertension. Hypoalbuminemia is common in pregnant women with preeclampsia but the impact of hypoalbuminemia on maternal and fetal morbidity in preeclampsia is not as yet well known.

Objectives: The study was designed to assess the serum levels of copper, ceruloplasmin, total proteins and albumin in gestational hypertension.

Methods: The study comprising of 50 healthy non- pregnant women, 50 healthy pregnant women and 50 women with gestational hypertension matched for age were assessed for serum ceruloplasmin, copper, total proteins and albumin.

Results: An increase in serum levels of copper and ceruloplasmin and decrease in total proteins and albumin in both pregnancy and gestational hypertension cases was observed compared to non-pregnant controls.

Conclusion: It was concluded from the present study that there is an increase in copper and ceruloplasmin and decrease in total proteins and albumin in both healthy pregnant and gestational hypertension cases but more pronounced in the latter.
\end{abstract}

Key words: gestational hypertension, oxidative stress, serum ceruloplasmin

\section{Introduction}

Pregnancy is a condition exhibiting increased susceptibility to oxidative stress, that becomes more pronounced in preeclampsia. Preeclampsia, more prevalent in first pregnancies is associated with the highest maternal and fetal morbidity and mortality of all the pregnancy complications [1,2].

Preeclampsia is a rise in blood presure with proteinuria and gestational hypertension is a rise in blood pressure without proteinuria during the second-half of pregnancy. The diagnosis of gestational hypertension covers women with the preeclampsia who have not yet manifested proteinuria as well as women who do not have the preeclampsia syndrome [3]. Approximately $50 \%$ of women with gestational hypertension with onset at $<30$ weeks develop preeclampsia [4].

Preeclampsia is associated with lipid peroxidation and is a key contributing factor to the pathophysiologic condition of preeclampsia. High levels of serum hydroperoxides and increased susceptibility of lipid peroxidation indicates preeclampsia to be associated with high oxidative stress [5]. Oxidative stress is a disturbance in the prooxidant antioxidant balance leading to potential damage. The ischemia/reperfusion injury associated with preeclampsia promotes both placental damage and release of factors leading to maternal endothelial dysfunction, and it has been postulated that alteration in the antioxidant activity may enhance endothelial cell oxidative damage. [6,2] Studies regarding the antioxidant status in gestational hypertension are varied $[7,8,9]$.

Whilst proteinuria (defined here as the urinary excretion of $\geq 0.3 \mathrm{~g}$ protein in a 24 -hour specimen), is not essential for the diagnosis of preeclampsia, it is the common clinical and diagnostic feature of the disorder in women with hypertension[10].

Preeclampsia is considered to be associated with increased vascular permeability leading to albumin loss from the intravascular spaces. Although hypoalbuminemia is common in pregnant women with preeclampsia, the impact of hypoalbuminemia on maternal and fetal morbidity in preeclampsia is not as yet well known [11]. 
Therefore the present study aimed at elucidating the effect of gestational hypertension on copper, ceruloplasmin, total proteins and albumin levels.

\section{Methods}

A cross-sectional study was undertaken in Dr Pinnamaneni Siddhartha Institute of Medical Sciences and Research Foundation, Chinna Avutapalli, Andhra Pradesh, India. This study was conducted over a period of 15 months February 2011 to April 2012. It included 150 women; comprising of three groups, 50 cases diagnosed with gestational hypertension, 50 cases of age matched normal pregnant women and 50 age matched non- pregnant women were included in our study. The patients were randomly selected from the Obstetrics and Gynecology Department of the Institute. The study was approved by Institutional ethical committee.

History was taken regarding age, parity, past history, family history and present history. General examination of all systems was done; blood pressure, pulse and respiratory rate were recorded. Blood pressure was recorded in the right arm in supine position and the fifth korotkoff sound was taken as the diastolic pressure.

Pregnant women who were primigravida with a sustained raise of blood pressure of $\geq 140 / 90 \mathrm{mmHg}$ (two measurements), with /without proteinuria were included in the study. Known cases of diabetes, hypertension or any systemic disorders were excluded from the study. Cases with haemoglobin levels $<11 \mathrm{~g} / \mathrm{dl}$ and having urinary tract infection were excluded from the study after screening.

Unhaemolyzed samples of $3 \mathrm{ml}$ venous blood was collected under aseptic conditions and were analyzed for copper, ceruloplasmin, total proteins, albumin, AST, ALT and creatinine levels. They were analyzed in the Randox-Daytona autoanalyzer. Estimation of ceruloplasmin was done by turbidometric method, copper by colorimetric method, total proteins by biuret method, albumin by bromocresol green method, liver enzymes AST and ALT, and serum creatinine by kinetic method. Urinary protein was estimated by dipstick method and $24 \mathrm{hr}$ urinary protein estimation.

Statistical analysis was done using graph pad prism version 6. ANOVA analysis was done to compare the variables. $\mathrm{P}$ value $<0.05$ was considered to be statistically significant.

\section{Results}

The mean age in years of the non-pregnant, normal pregnant and gestational hypertension cases were $22.7 \pm 1.66,23.18 \pm 2.10,25.58 \pm 2.40$ respectively. The mean systolic and diastolic pressure in $\mathrm{mm} / \mathrm{Hg}$ of the nonpregnant, normal pregnant and gestational hypertension cases were $120.68 \pm 11.14,125.78 \pm 7.88,149.7 \pm 6.17$ and $76.96 \pm 6.6,79.08 \pm 6.06,99.52 \pm 5.49$ respectively.

The mean gestational age in weeks of the normal pregnant women and women with gestational hypertension was $29.7 \pm 2.92$ and $29.18 \pm 3.32$ respectively

Proteinuria of $<1+$ ( traces) was detected in $6 \%$ of healthy pregnant women and in $23 \%$ of women with gestational hypertension by dipstick. $24 \mathrm{hrs}$ urinary protein estimation for these cases showed a value of < $100 \mathrm{mg}$ /day for normal pregnant and $<120 \mathrm{mg}$ /day for women with gestational hypertension. No proteinuria was detected in non pregnant women.

Comparison of various parameters of non-pregnant women with normal pregnant women and women with gestational hypertension has shown statistically significant increase in copper and ceruloplasmin levels and a statistically significant decrease in total proteins and albumin levels, with $\mathrm{p}<0.05$ for all the variables. Although mild increase of liver enzymes was noted in normal pregnant women and women with gestational hypertension, no statistical difference was noted for the liver enzymes and serum creatinine between the three groups [Table 1].

Table 1: Comparison of parameters in non- pregnant women, normal pregnant women and women with gestational hypertension

\begin{tabular}{|c|c|c|c|c|}
\hline Parameter & Non-pregnant & Normal pregnant & $\begin{array}{l}\text { Gestational } \\
\text { hypertension }\end{array}$ & $\mathrm{p}$ value \\
\hline $\mathrm{N}$ & 50 & 50 & 50 & \\
\hline Copper $(\mu \mathrm{g} / \mathrm{dl})$ & $112.9 \pm 13.15$ & $119.8 \pm 15.37$ & $154.8 \pm 19.93$ & $<0.0001$ \\
\hline Ceruloplasmin $(\mathrm{mg} / \mathrm{dl})$ & $43.39 \pm 1.39$ & $50.41 \pm 0.91$ & $68.71 \pm 13.12$ & $<0.0001$ \\
\hline Total proteins $(\mathrm{g} / \mathrm{dl})$ & $6.75 \pm 0.55$ & $5.99 \pm 0.86$ & $5.49 \pm 0.66$ & $<0.0001$ \\
\hline Albumin $(\mathrm{g} / \mathrm{dl})$ & $4.48 \pm 0.57$ & $4.10 \pm 0.64$ & $3.85 \pm 0.62$ & $<0.0001$ \\
\hline AST (IU/L) & $17.9 \pm 4.87$ & $19.9 \pm 5.69$ & $22 \pm 7.17$ & 0.23 \\
\hline ALT(IU/L) & $18.5 \pm 5.46$ & $20.6 \pm 5.59$ & $23.3 \pm 7.35$ & 0.12 \\
\hline Creatinine $(\mathrm{mg} / \mathrm{dl})$ & $0.75 \pm 0.2$ & $0.75 \pm 0.17$ & $0.79 \pm 0.22$ & 0.56 \\
\hline
\end{tabular}




\section{Discussion}

Preeclampsia occurs after the $20^{\text {th }}$ week of gestation. It is a placental dependent disorder with both local intrauterine and systemic signs and symptoms. It has been proposed that the pathophysiology of preeclampsia develops in two stages, with reduction in placental perfusion as stage 1 of preeclampsia and the maternal syndrome as stage 2 . It has been suggested that oxidative stress is responsible for the transition from stage one to stage two [12].

Recent evidence indicates an increased inflammatory response in normal pregnancy that is further augmented in preeclampsia[13].There are suggestions that nutrients or micronutrients may modify the inflammatory response [14]. Copper is an essential cofactor for many enzymes including cytochromes, but it is toxic in its unbound form. Therefore it can act as a pro-oxidant as well as antioxidant. During pregnancy plasma copper concentration significantly increases, returning to normal non pregnant values after delivery. The increase in copper with the progression of pregnancy could be partly related to synthesis of ceruloplasmin, a major copper binding protein due to altered levels of oestrogen [15].

Ceruloplasmin is an acute phase reactant and its expression has been shown to increase under hypoxic conditions [16]. Concentrations of the acute phase reactants are up regulated during infection, inflammation and tissue trauma, mediated by inflammatory cytokines. [17]

Ceruloplasmin has ferroxidase activity and since long, has also been considered as a plasma antioxidant due to its ability to react with and scavenge toxic substances like superoxide and hydrogen peroxides [18].

Studies have shown that placental factors are involved in the pathophysiology of preeclampsia. It has been postulated that in severe preeclampsia there is an increase in placental ceruloplasmin following hypoxia, indicating that placental ceruloplasmin, a protein with antioxidant properties expression is clearly upregulated in the preeclampsia groups [6].

Our study showed statistical significant rise in the serum copper and ceruloplasmin levels in healthy pregnant women and in women with gestational hypertension, on comparison with non-pregnant women. These findings were in agreement with other studies $[9,19,20]$.

Studies have demonstrated proteinuria in normal pregnant women and women with gestational hypertension. In Preeclampsia there is marked hypofiltration due to reduction in renal plasma flow and GFR. There is a loss of glomerular barrier charge and size selectivity which normalizes postpartum [21]. Hypoalbuminemia is explained by an increase in plasma and interstitial volume and possibly by an increase in albumin metabolism. Increase in capillary permeability secondary to endothelial damage seems to be partly responsible for this finding [22].

Adedeji AL et al [23] has observed that compared with non pregnant women, the concentration of total proteins, albumin, were not significantly decreased in normotensive pregnant women. Olooto WE et al [24] and Arinola $\mathrm{G}$ et al [25], showed that total proteins and serum albumin levels were significantly decreased while urinary protein was significantly increased in pregnancy related hypertension and preeclampsia groups respectively as compared to normal pregnant women

Our study showing a statistical significant decrease in total proteins and albumin levels in healthy pregnant women and in women with gestational hypertension compared to non pregnant women and is in accordance with the above studies.

Key points

- Gestational hypertension /preeclampsia is a multisystem disorder based on a cascade of immunopathological events originating from the placenta. No single candidate mechanism exists to explain the complex pathogenesis.

- From present study it is concluded that the increase in ceruloplasmin levels appear to be secondary to oxidative stress and an increase in copper levels to the fact, that incorporation of copper is essential for ceruloplasmin activity. A decrease in glomerular filtrate rate and renal blood flow probably accounts for a decrease in the levels of total proteins and albumin. 


\section{References:}

[1]. Burton G J, Jauniaux E. Oxidative stress. Best Pract Res Clin Obstet Gynaecol. 2011; 25(3): $287-299$.

[2]. Fialová L, Kalousová M, Soukupová J, Malbohan I et al. Markers of Inflammation in Preeclampsia. Prague Med Rep. 2004 ;105 (3): 301-310.

[3]. Lindheimer, Sandra J, Taler, Cunningham F G. ASH Position Article. Hypertension in pregnancy. J Am Soc Hypertens. 2008; 2 (6): 484-494.

[4]. Sibai BM, Diagnosis and Management of Gestational Hypertension and Preeclampsia Obstet Gynecol. 2003;102:181-92.

[5]. Pyska W, Klejewski A. Karolkiewics J, Szczesniak L, Szczesniak - Chmielecka A et al. Imbalance of pro-oxidants - antioxidants in blood of pregnant women with pregnancy induced hypertension. Ginekol Pol 2002; 73: 14 - 8 (in Polish).

[6]. Guller S, Buhimschi CS, Ma YY, Huang ST, Yang et al. Placental expression of ceruloplasmin in pregnancies complicated by severe preeclampsia. Lab Invest. 2008; 88: 1057 - 1067.

[7]. Rathore S, Gupta A, Batra HS, Rathore R. Comparative study of trace elements and serum ceruloplasmin level in normal and preeclamptc pregnancies with their cord blood. Biomed Res. 2011; 22 (2): 207-210.

[8]. Mahomed K, Williams MA, Woelk GB, Mudzamiri S, Madzime S et al. Leukocyte, selenium, zinc and copper concentrations in preeclampsia and normotensive pregnant women. Biol Trace Elem Res 2004; 75: 107-118.

[9]. Ajose A, Fasuba B, Anetor JI, Adelekan DA, Makinde NO. Serum zinc and copper concentrations in Nigerian women with normal pregnancy. Nig. Postgraduate Med J 2001; 8: 161 - 164.

[10]. Walker J J. Pre-eclampsia. Lancet 2000; 356: 1260-65.

[11]. KimYO, Yoon SA, Kim YS, Kim MK, Hong SH, Chang YS et al. The impact of serum albumin levels on maternal and fetal morbidity in women with preeclampsia, Korean J Med 2003; 65(2): 224 -230.

[12]. Robert JM., Hilary S. Gammill. Preeclampsia: Recent insights. Hypertension 2005;46:1243 - 1249

[13]. Germain S J, Sack G P, Soorana SR, Sargent I L, Redman C W. Systemic Inflammatory Priming in Normal Pregnancy and Preeclampsia:The Role of Circulating Syncytiotrophoblast Microparticles. J Immunol. 2007;178: 5949 -5956.

[14]. Roberts JM, Balk JL, Bodnar LM, Beliza’ JM, Bergely E, Martinez A. Nutrient Involvement in Preeclampsia. J Nutr . 2003;133: $1684 \mathrm{~S}-1692 \mathrm{~S}$.

[15]. Liu J, Yang H, Shi H et al. Blood copper, zinc, calcium, and magnesium levels during different duration of pregnancy in Chinese. Biol Trace Elem Res: 2010; 135(1): $31-37$.

[16]. Gabay C, Kushner I. Acute-phase Proteins. Encyclopedia of life sciences / (C 2001 nature publishing group / www.els.net

[17]. Sarkar J, Seshadri V, Tripoulas NA et al. Role of ceruloplasmin in macrophage iron efflux during hypoxia. J Biol Chem. 2003; 278: $44018-44024$.

[18]. Patel BN, Dunn RJ, Jeong SY, Zhu Q, Julien JP et al: Ceruloplasmin regulates iron levels in the CNS and prevents free radical injury. J Neurosci. 2002; 22: 6578-6586.

[19]. Serdar Z, Gur E, Develioglu O, Serum iron and copper status and oxidative stress in severe and mild preeclampsia. Cell Biochem Funct : 2006; 24(3): $209-215$.

[20]. Aksoy H, Taysi S, Altinkaynak K, Bakan E, Bakan N et al. Antioxidant potential and transferrin, ceruloplasmin, and lipid peroxidation levels in women with preeclampsia. J Investig Med. 2003 ;51(5):284-7.

[21]. Moran P, Baylis PH, Lindheimer MD, Davison JM. Glomerular ultrafiltration in normal and preeclamptic pregnancy. J Am Soc Nephrol. 2003; 14: 648-52.

[22]. Homer CS, Brown MA, Mangos G, Davis Gk. Non- proteinuric preeclampsia: a novel risk indicator in women with gestational hypertension. J. Hypertens. 2008; 26: 295 - 302.

[23]. Adedeji AL, Adedosu OT, Afolabi OK, Badmus JA, Ehigie LO et al. Serum protein profile in Nigerian women: an analysis by gestation age. Researcher. 2012; 4(11):38-42.

[24]. Olooto WE, Amballi AA, Mosuro, Adeleye AA, Banjo TA. Assessment of total protein, albumin, creatinine and aspartate transaminase level in toxaemia of pregnancy. J.med sci. 2013; 13(8):791-796.

[25]. Arinola G, Arowojolu A, Bamgboye A, Akinwale A, Adeniyi A. Serum concentrations of immunoglobulins and acute phase proteins in Nigerian women with preeclampsia. Reprod Biol. 2006 ;6(3):265-74. 